\title{
BMJ Open Are Australians ready for warning labels, marketing bans and sugary drink taxes? Two cross-sectional surveys measuring support for policy responses to sugar-sweetened beverages
}

Caroline L Miller, ${ }^{01,2}$ Joanne Dono, ${ }^{2,3}$ Melanie A Wakefield, ${ }^{4,5}$ Simone Pettigrew, ${ }^{6}$ John Coveney, ${ }^{7}$ David Roder, ${ }^{8}$ Sarah J Durkin, ${ }^{\oplus, 5}$ Gary Wittert, ${ }^{9,10}$ Jane Martin, ${ }^{11}$ Kerry A Ettridge $\mathrm{e}^{2,3}$

To cite: Miller CL, Dono J, Wakefield MA, et al. Are Australians ready for warning labels, marketing bans and sugary drink taxes? Two cross-sectional surveys measuring support for policy responses to sugar-sweetened beverages. BMJ Open 2019;9:e027962. doi:10.1136/ bmjopen-2018-027962

- Prepublication history and additional material for this paper are available online. To view these files, please visit the journal online (http://dx.doi. org/10.1136/bmjopen-2018027962).

Received 15 November 2018 Revised 29 March 2019 Accepted 4 June 2019
Check for updates

(C) Author(s) (or their employer(s)) 2019. Re-use permitted under CC BY-NC. No commercial re-use. See rights and permissions. Published by BMJ.

For numbered affiliations see end of article.

Correspondence to Dr Caroline L Miller; caroline.miller@sahmri.com

\section{ABSTRACT}

Objective To assess public support for 10 potential policy initiatives to reduce sugar-sweetened beverage (SSB) consumption.

Design A 2014 historical data set, which employed a face-to-face survey in one Australian state (study 1), provided the basis for comparison with our 2017 nationally representative, cross-sectional, computer-assisted telephone interviewing population survey (study 2).

Participants Study 1: South Australians, 15+ years $(n=2732)$; study 2 : Australians, $18+$ years $(n=3430)$. Primary outcome measures: levels of support for SSB-specific policy initiatives. For the 2017 national study (study 2), demographic characteristics, body mass index, knowledge of potential harms caused by consuming SSBs and SSB consumption were included in multivariable regression analyses.

Results In 2017, all 10 potential policy initiatives received majority support $(60 \%-88 \%$ either 'somewhat' or 'strongly' in favour). Initiatives with educative elements or focused on children received high support (>70\%), with highest support observed for text warning labels on drink containers (88\%) and government campaigns warning of adverse health effects (87\%). Higher support was observed for SSB tax paired with using funds for obesity prevention (77\%) than a stand-alone tax (60\%). Support for policy initiatives was generally greater among those who believed SSB daily consumption could cause health problems in adults (4\%-18\% absolute difference) and/or in children (8\%-26\% absolute difference) and lower among SSB high consumers (7+ drinks per week; 9\%-29\% absolute difference). State-specific data comparison indicated increased support from 2014 to 2017 for taxation $\left(42 \% v s 55 \% ; \chi^{2}=15.7, p<0.001\right)$ and graphic health warnings (52\%vs68\%; $\chi^{2}=23.4$. $\mathrm{p}<0.001$ ).

Conclusions There is strong public support for government action, particularly regulatory and educational interventions, to reduce SSB consumption, which appears to have increased since 2014. The findings suggest that framing policies as protecting children, presenting taxation of SSBs in conjunction with other obesity prevention
Strengths and limitations of this study

- A large nationally representative study of 3430 Australian adults enabled current (2017) insight into level of support for policy initiatives specifically aimed at reducing sugar-sweetened beverage (SSB) consumption.

- A second large historical data set of 2732 from one Australian state enabled a historical comparison to provide indication of how opinions have changed over the last 3 years (2014).

- The study provides current insight into the characteristics of supporters and non-supporters (including knowledge about SSBs) of different policy support options.

- Results are limited by the cross-sectional nature of the surveys.

- Historical comparison is limited by the methodological differences between the two data sets.

initiatives and education focused on the harms associated with SSB consumption will increase support.

\section{INTRODUCTION}

Excess consumption of sugar-sweetened beverages (SSBs) is causally associated with increased risk of obesity, type II diabetes, periodontal disease, dental caries and cardiovascular disease. ${ }^{1-6}$ SSB consumption is high in Australia as it is in other countries, ${ }^{7}$ with one-third of the Australian population (34\%) reporting they had consumed SSBs on the day prior to the National Health Survey. ${ }^{8}$ SSB consumption (prior day) was found to be higher among Australian men than women (39\% vs 29\%) and highest among those from disadvantaged areas $(47 \%) .^{8}$ Consumption increased with age and peaked at $62 \%$ among adolescent males aged 14-18 years. 
Australian adults who consumed SSBs on the day prior to the National Health Survey ingested an average of 13 teaspoons $(54 \mathrm{~g})$ of sugar from SSBs daily, and adolescent males consumed, on average, 16 teaspoons of sugar $(68 \mathrm{~g}) .{ }^{8}$ This is concerning given the WHO recommends limiting total daily free sugar consumption to $10 \%$ of total energy intake, which equates to approximately 13 teaspoons. ${ }^{9}$ SSBs represent a significant source of added sugar in the Australian diet and a readily modifiable risk factor for many prevalent chronic diseases.

Attention has increased on SSB consumption as a target for population-level and policy-level interventions worldwide. Policy-level interventions may include taxes or health levies (taxes imposed on products coupled with investment in prevention programmes and/or health costs associated with obesity), changes to product (labelling and size restrictions), restricting marketing practices and reducing availability. More than 30 jurisdictions around the world have implemented SSB taxes, ${ }^{10}$ and a number of postimplementation studies provide realworld evidence of their effectiveness. ${ }^{10-12}$ Implementation of other interventions, such as mandatory menu kilojoule labelling, advertising restrictions or health warnings, is far less widespread. ${ }^{13}$

Substantial political support is required to implement regulatory interventions due to strong industry opposition. ${ }^{14-17}$ It is widely recognised that public support is an important factor influencing political appetite for policy reform and therefore implementation. ${ }^{18-21}$ Policy makers benefit from, and are sensitive to, data on how potential policy initiatives are perceived by the community, in addition to data on effectiveness. ${ }^{22-24}$ In turn, the degree to which people are knowledgeable about a health issue may influence the degree to which they support policy options aimed at changing health behaviours. ${ }^{25}{ }^{26}$ Identifying levels of public knowledge and support for interventions, as well as the characteristics of members of the community who support various initiatives, can also assist public health agencies and advocates in developing effective message framing for encouraging evidence-based policy reform. 2728

Published data on public support for regulatory initiatives specifically aimed at SSB consumption is limited in the Australian context. The majority of studies including data relating specifically to support for SSB policy initiatives have reported on US populations, ${ }^{18} 29-33$ with some surveys also conducted in other high-income countries. ${ }^{34-38}$ Many of these studies have focused on taxes, with and/or without complementary funding for obesity prevention or health. ${ }^{29}{ }^{31-36} \mathrm{Few}$ studies have compared levels of support across different SSB policy options. ${ }^{30} 323739$ While estimates of support may not be directly comparable across countries and jurisdictions, some general patterns emerge. Overall, initiatives that have been received more positively include those that are less intrusive and incorporate elements of 'nudge' strategies. These include coupling revenue from tax with investment into the health system or complementary educative initiatives, targeting consumption in children and/or educating consumers on health effects of consumption. ${ }^{30} 32$ 35-37 3940 Policy interventions that have received lower levels of support include: stand-alone taxes and restrictions on SSB availability or promotion. ${ }^{30} 3239$

To date, Australian studies have been conducted on non-representative samples ${ }^{36} 39$ and/or have focused on foods and beverages concurrently, with few questions directly assessing SSB-specific initiatives. ${ }^{36}{ }^{37} \mathrm{~A}$ recent online study ${ }^{37}$ indicated that the Australian public is supportive of government regulation to prevent obesity and overweight in general (86\%), with substantial support for initiatives to restrict advertising of unhealthy foods and beverages in a number of contexts, especially restriction of advertising to children on television $(79 \%)$ and via the internet $(76 \%)$. In relation to SSBs specifically, $55 \%$ supported a tax on SSBs and 63\% supported prohibiting sponsorship of children's sport. A 2010 study of a sample of household grocery buyers found approximately $70 \%$ support for a tax on soft drinks if the revenue raised was used to reduce the cost of healthy food, with levels of support higher among parents and those of higher socioeconomic status. ${ }^{36} \mathrm{~A}$ study of Australian university students and staff's views on SSB-specific interventions on-campus indicated high support $(>75 \%)$ for increasing access to free drinking water, lowering the price of water and diet beverages and educational initiatives (nutrition information and campaigns). ${ }^{39}$ Lower support $(<50 \%)$ was reported for removing SSBs from display, replacing SSBs with diet or low sugar versions, or restricting sales of SSBs on-campus. A 2016 public opinion poll in Australia indicated $75 \%$ would either 'strongly' or 'probably' support a tax on SSBs with 'high levels of sugar if revenues raised were used to fund programs to reduce the damaging health effects of SSB consumption'. ${ }^{41}$ In a 2018 Australian poll, where there was no mention of the use of funds raised, 53\% indicated they would support a tax on SSBs. ${ }^{42}$

Data on public support for SSB policy initiatives beyond taxation are very limited. As SSBs have been specifically identified for intervention by the WHO due to their significant contribution to free sugar intake and the over consumption of energy, ${ }^{9}$ it is important to gauge public response to other potential SSB-targeted initiatives. Assessing public levels of support for policy initiatives aimed at reducing consumption of unhealthy food within the same question as SSBs may obscure the level of support evident for SSB-targeted initiatives. While experimental evidence regarding effectiveness of SSB warning labels is increasing, ${ }^{43-46}$ a substantial knowledge gap exists around public acceptability of warning labels on SSBs as a policy initiative relative to other SSB policy initiatives such as taxation. Warning labels both educate and deter consumers and have shown effectiveness in increasing consumers' understanding of the harm caused by smoking and reducing tobacco consumption. ${ }^{47}$ Evidence of the potential effectiveness of warning labels in changing 
dietary behaviour is increasing. ${ }^{46}{ }^{48-52}$ Warning labels for SSBs are of growing interest to policy makers. While some estimates of policy support have been derived from online experimental studies, ${ }^{46} 48$ population estimates of the acceptability of warning label policies are lacking.

We sought to determine levels of public support for different types of policies targeted specifically at SSBs and how levels of support vary according to sociodemographic factors, health risk factors and levels of knowledge. Such data will help inform the political feasibility of the range of potential interventions. This paper presents results from two large, representative population studies: a state-based survey conducted in 2014 and a national survey conducted in 2017. Together, the findings provide a current picture of policy support among Australians as well as an indication of how views may have changed in the past 3 years within one state.

\section{METHOD}

\section{Study 1: 2014 state-based population survey}

SSB policy support questions were developed and included in the 2014 South Australian Health Omnibus Survey (SA HOS), an annual, representative population survey of residents aged 15 years and older, administered via face-to-face interviews between September and December. The survey employed a multistage, stratified, random sampling strategy to identify households in South Australia (SA), with one interview conducted per household with the person who had the most recent birthday. An approach letter detailing study information was sent to the house 2 weeks prior to the interview, and up to six follow-up visits were made to secure the interview. Further detail regarding sampling, recruitment methods and data weighting procedures have been previously published. ${ }^{53}$

The policy support questions were based on similar measures successfully used to explore support for policies in tobacco and food contexts, ${ }^{3654}$ with content developed in consultation with coauthors and in consultation with Obesity Policy Coalition (a leading Australian advocacy organisation in obesity) (see supplementary material for a fully copy of the measure; online supplementary table S1). Support for eight policy initiatives was assessed (see table 1 and online supplementary table S1) by asking participants to indicate whether they were in favour of or against each initiative (presented in fixed order due to methodological constraints). For example, participants were asked 'Are you in favour or against the government taxing drinks that are high in added sugar?' with possible responses: strongly against, somewhat against, neither in favour or against, somewhat in favour and strongly in favour. Data were weighted to adjust for (inverse) probability of selection in the household (chance of selection given

Table 1 Support for SSB policy options in South Australia (2014 survey, $n=2732$ )

\begin{tabular}{|c|c|c|c|c|c|}
\hline \multirow[b]{3}{*}{ Policy option } & \multicolumn{2}{|c|}{ Proportion in favour } & \multirow{2}{*}{$\begin{array}{l}\text { Proportion } \\
\text { neither for nor } \\
\text { against }\end{array}$} & \multicolumn{2}{|c|}{ Proportion against } \\
\hline & Strongly & $\begin{array}{l}\text { Strongly/ } \\
\text { somewhat }\end{array}$ & & Strongly & $\begin{array}{l}\text { Strongly/ } \\
\text { somewhat }\end{array}$ \\
\hline & $\%(95 \% \mathrm{Cl})$ & $\%(95 \% \mathrm{Cl})$ & $\%(95 \% \mathrm{Cl})$ & $\%(95 \% \mathrm{Cl})$ & $\%(95 \% \mathrm{Cl})$ \\
\hline $\begin{array}{l}\text { Government tax on drinks high in } \\
\text { added sugar }\end{array}$ & $18(17-19)$ & $42(40-44)$ & $11(10-12)$ & $25(23-27)$ & $45(43-47)$ \\
\hline $\begin{array}{l}\text { Government funded TV campaigns } \\
\text { warning about health effects of } \\
\text { obesity }\end{array}$ & $43(41-45)$ & $80(79-81)$ & $9(8-10)$ & $3(2-4)$ & $10(9-11)$ \\
\hline $\begin{array}{l}\text { Restrictions on the sales of sugary } \\
\text { drinks at schools }\end{array}$ & $58(56-60)$ & $83(82-84)$ & $6(5-7)$ & $3(2-4)$ & $10(9-11)$ \\
\hline $\begin{array}{l}\text { Restrictions on the marketing of } \\
\text { sugary drinks to children through } \\
\text { websites and computer games }\end{array}$ & $59(57-61)$ & $84(83-85)$ & $6(5-7)$ & $4(3-5)$ & $10(9-11)$ \\
\hline $\begin{array}{l}\text { Restrictions on sugary drink } \\
\text { sponsorship of children's sport }\end{array}$ & $42(40-44)$ & $70(68-72)$ & $13(12-14)$ & $4(3-5)$ & $15(14-16)$ \\
\hline $\begin{array}{l}\text { Restrictions on advertising sugary } \\
\text { drinks to children on television }\end{array}$ & $55(53-57)$ & $80(79-81)$ & $8(7-9)$ & $4(3-5)$ & $11(10-12)$ \\
\hline $\begin{array}{l}\text { Written labelling on sugary drinks } \\
\text { warning about the risk of diabetes, } \\
\text { obesity and tooth decay }\end{array}$ & $53(51-55)$ & $85(84-86)$ & $6(5-7)$ & $3(2-4)$ & $8(7-9)$ \\
\hline $\begin{array}{l}\text { Graphic health warning labels } \\
\text { on sugary drinks like those on } \\
\text { cigarettes }\end{array}$ & 27 (25-29) & $52(50-54)$ & $13(12-14)$ & $12(11-13)$ & $34(32-36)$ \\
\hline
\end{tabular}

Note: Percentages do not add up to $100 \%$ as less than $2 \%$ reported 'don't know' or 'refused' for each response. 'Strongly/somewhat' reflects the cumulative proportion of those reporting they were either strongly or somewhat in favour, or strongly or somewhat against. 
the number of eligible people in the household) and response rate (RR) (metropolitan and country regions). Data were then reweighted to reflect population characteristics of age, sex and geographical area in SA. ${ }^{55}$

\section{Study 2: 2017 national survey}

A survey was conducted with a national sample of adults, with the following eligibility criteria applied: aged 18 years or older, able to converse in English and living in Australia. The Social Research Centre was commissioned to recruit participants and conduct surveys via computer-assisted telephone interview (CATI). Participants were contacted via random digit dialling to a landline or mobile phone number at a ratio of 35:65, which is in accordance with Australians' use of communication. ${ }^{56}$ For landlines, where more than one eligible respondent resided in the household, preference was given to the youngest eligible male, followed by the youngest eligible female, as these groups can be under-represented in telephone surveys. ${ }^{57}$ The person who answered the phone was the selected respondent from the mobile sample provided they met the eligibility criteria. Interviewers provided a brief introduction to the study and then ascertained participants' eligibility and willingness to continue in the study. The sample size $(\mathrm{n}=3600)$ was selected to provide an accurate representation of opinions of Australian adults and also to allow for the detection of differences in knowledge following any future policy adoption in Australia.

\section{Measures}

Policy questions were based on measures used in study one with minor adaptations. To mitigate ceiling effects suggested by the South Australian survey data and based on consultation with an obesity advocacy expert from the Obesity Policy Coalition, some of the initiatives were modified in 2017 to represent a tougher policy stance, for example, initiatives suggesting 'restriction' in 2014 were changed to 'banning' in 2017. A question was also included to obtain a more nuanced understanding of policy conditions; for example, an initiative proposing using the funds raised from taxes for obesity prevention was added. One question was amended to reflect the evolution of digital technology (see online supplementary table S1 in supplementary material for a full description of wording changes from 2014 to 2017).

For ease of interpretation, SSBs were referred to as 'sugary drinks' throughout the survey and were defined as soft drinks, energy drinks, sports drinks, fruit-flavoured mineral waters, all types of fruit juice and cordial. Participants were asked to what extent they were in favour or against 10 potential policy initiatives presented in random order, except for the initiative pertaining to a SSB tax that always preceded the extension of this initiative (ie, using money raised to fund obesity prevention) (see online supplementary table S1, supplementary material, for all policy options presented). For example, participants were asked, 'Are you in favour or against government funded TV campaigns educating people about the health effects of sugary drinks?' with possible responses: strongly against, somewhat against, neither in favour or against, somewhat in favour and strongly in favour.

Consistent with previous studies, ${ }^{53589}$ weekly consumption was estimated by asking participants on how many days they had consumed sugary drinks in the past 7 days and how much they normally consumed (number of $250 \mathrm{~mL}$ cups) on a day when they consumed sugary drinks. To enable a calculation of body mass index (BMI), participants reported their weight and height. For ease of interpretation, patients were subsequently categorised as either overweight/obese (BMI of 25 or more) or healthy/underweight (BMI under 25) as we were interested in perceptions of policies among those who were overweight/obese, and those in the underweight range comprised only $3 \%$ of the sample. Two knowledge questions, based on measures used previously in a US sample ${ }^{60}$ asked participants to indicate the likelihood of developing any health problems later in life if: (1) an adult and (2) a child consumed a sugary drink every day. A pilot of 30 interviews was conducted prior to full implementation of the study, and some questions were slightly revised to improve comprehension. Specific questions assessing SSB consumption, BMI and knowledge are available from online supplementary table S2 in supplementary material.

\section{Sociodemographics}

Participants' sex, age, education, employment status, postcode and main language spoken at home were recorded. Postcodes were used to calculate level of disadvantage scores according to the Australian Bureau of Statistics' Socio-Economic Indexes for Areas, ${ }^{61}$ which were grouped to form 'most disadvantaged' (deciles 1-3); 'moderately disadvantaged' (deciles 4-7) and 'least disadvantaged' (deciles 8-10) categories.

\section{Statistical analyses}

Data were weighted to adjust for individuals' chances of selection according to relevant population benchmarks for age, sex, location and telephony status sourced from Australian government data. ${ }^{62}{ }^{63}$ Wilcoxon signed-ranks tests were used to compare responses to policy questions. $\chi^{2}$ tests were conducted to examine differences in support for each initiative between the 2014 sample and a comparative state subset of the 2017 sample. For multivariable analyses, responses were dichotomised to be either: 'in favour' (strongly or somewhat) or 'not in favour' (strongly against, somewhat against or neither for nor against), as a minority (3\%-4\%) indicated they were 'neither for nor against'. Multivariable logistic regression analyses were conducted to identify characteristics of those in favour of each policy initiative in terms of sociodemographic characteristics, levels of knowledge, SSB consumption and BMI. These analyses were adjusted for all other factors as we were interested in unique variance explained. Only factors found to explain unique variance in any one policy initiative were reported in the multivariable results table 
(for ease of interpretation). All analyses were conducted on unweighted and weighted data with a small degree of variation apparent in results: the strength and significance of associations changed slightly for a minority of results, with no change at the conventional $\mathrm{p}<0.05$ level. Due to the small degree of difference in results, results of analyses on weighted data are presented here.

\section{Patient and public involvement}

Patients and members of the public were not involved in the development of the research question, outcome measures, study design, recruitment or conduct of the studies. Results will be disseminated to participants of the 2017 National Survey who registered their interest in receiving a report at the completion of the project.

\section{RESULTS}

\section{4 state-based population survey results}

Of the initial sample drawn $(n=5200)$, there were interviews completed for 2732 participants with 183 considered out of scope (vacant houses, businesses). According to the American Association for Public Opinion Research (AAPOR), which offers standardised formulas for calculating appropriate responses to surveys, this yields an RR1 (participants completing the survey as a proportion of eligible sample) of $55 \%$ and a participation rate of $61 \%$ (denominator excluded 507 dwellings for which contact could not be established after six attempts) ${ }^{64}$ The sample had a good representation of sociodemographic characteristics (ie, gender, age, education and socioeconomic disadvantage), which has been published previously. ${ }^{53}$

There was greater than $80 \%$ support for five out of the eight policy options (text warning labels; restrictions on advertising to children via television and via websites/games; restrictions on sales in schools; and television campaigns) (see table 1). Support was lower, but still favoured by the majority, for restricting sugary drink sponsorship of children's sport $(70 \%)$ and adding graphic warning labels to sugary drink containers (52\%). Responses to taxing sugary drinks were mixed, with approximately equivalent proportions in favour and against taxation.

\section{7 national survey results}

The AAPOR RR3 for this study was $16 \%$, that is, the number of completed interviews as a proportion of all interviews (complete and partial), refusals, non-contacts and those with unknown eligibility that were estimated to be eligible. ${ }^{64}$ A participation rate of $44 \%$ was achieved (slightly lower than for study 1: $55 \%$ ), resulting in 3430 participants.

Table 2 describes participants' characteristics, SSB knowledge and consumption behaviour. The distribution of the weighted sample was similar to that of 2016 Australian census population data with respect to sex, age and employment status, ${ }^{65}$ though participants of the current study had slightly higher levels of education, socioeconomic status and English as their main language (survey eligibility required proficiency in English). Sugary drink consumption was higher in the current sample, yet the proportion of overweight/obese participants was slightly lower. These differences are likely due to variation in assessment methods (eg, current study reported usual consumption, whereas the Australian Bureau of Statistics reported previous day's consumption) ${ }^{8}$ and historical nature of the comparative data sets, ${ }^{66}$ and therefore, only a general level of comparison can be made. Overall, the sample was considered representative of the Australian population, as it was equivalent to census data in terms of age, sex and employment status and approximated level of education and socioeconomic status.

All policy options received majority support ranging from $60 \%$ to $88 \%$ (see table 3 ). Interventions with a consumer warning or educative focus received very high levels of support. Over $80 \%$ of participants reported that they were either strongly or somewhat in favour of: text warning labels on SSB containers about health risks; government-funded TV campaigns about the health effects of SSBs; text warning labels on vending machines and other places of sale; and text warning labels on SSB advertisements (eg, billboards and television). Potential interventions involving banning marketing or sales also received high levels of support $(71 \%-79 \%)$. There were significant differences observed in support between all of the policy options assessed. Of particular note, government tax on drinks high in added sugar received majority support at $60 \%$; however, support was substantially higher for SSB tax $(77 \%)$ when paired with the complementary measure of reinvesting revenue into obesity prevention $(\mathrm{Z}=-25.0 ; \mathrm{p}<0.001)$.

The 2017 national sample included data from all Australian states and territories, enabling a comparison between the SA subset $(n=247)$ and the 2014 South Australian Health Omnibus Survey (SA HOS) data (previously described study $1 ; n=2732$ ). There was a statistically significant difference between the comparably worded initiatives of support for taxation of SSBs (42\% in 2014 compared with 55\% in 2017; $\left.\chi^{2}=15.7, \mathrm{p}<0.001\right)$ and graphic health warnings on SSBs (52\% in 2014 and $68 \%$ in 2017, $\left.\chi^{2}=23.4 . p<0.001\right)$.

\section{Sociodemographic predictors of support for SSB policy options}

There was little variation in support for consumer warning/educative policy initiatives by sociodemographic characteristics (see table 4). However, there was significantly higher support for graphic warning labels among females than males and among older than younger participants. While support for text warning labels on SSB adverts varied significantly by level of disadvantage such that support was slightly lower among those from least disadvantaged areas, absolute difference in percentages was small.

There was greater sociodemographic variation observed for the marketing, sales and taxation policies (see table 5). Females reported significantly higher support than males 
Table 2 Sociodemographic characteristics and prevalence (\%) of risk factors and knowledge variables

\section{Current study \\ $(n=3430)$}

$\begin{array}{lll}\begin{array}{l}\text { Proportion (\%) of } \\ \text { participants (weighted) }\end{array} & \text { Proportion (\%) of } & \text { Proportion (\%) of } \\ \text { participants (unweighted) } & \text { participants }\end{array}$

\section{Sociodemographic characteristics}

participants (weighted) participants (unweighted) participants

\begin{tabular}{|c|c|c|c|}
\hline \multicolumn{4}{|l|}{ Sex } \\
\hline Female & 49 & 49 & 51 \\
\hline Male & 51 & 52 & 49 \\
\hline \multicolumn{4}{|l|}{ Age range (years) } \\
\hline $18-30$ & 24 & 15 & 24 \\
\hline $31-45$ & 24 & 20 & 27 \\
\hline $46-60$ & 26 & 27 & 24 \\
\hline $61+$ & 26 & 37 & 25 \\
\hline \multicolumn{4}{|l|}{ Level of education } \\
\hline Secondary school or less & 27 & 28 & 40 \\
\hline $\begin{array}{l}\text { Some tertiary education or completed } \\
\text { vocational training }\end{array}$ & 34 & 33 & 33 \\
\hline Finished university (bachelor degree or higher) & 38 & 37 & 26 \\
\hline \multicolumn{4}{|l|}{ Level of disadvantage (deciles) } \\
\hline Decile 1-3 (most disadvantaged) & 20 & 21 & 29 \\
\hline Decile 4-7 (mid) & 41 & 40 & 40 \\
\hline Decile 8-10 (least disadvantaged) & 38 & 39 & 31 \\
\hline \multicolumn{4}{|l|}{ Employment status } \\
\hline Work full or part time & 60 & 55 & 62 \\
\hline Not currently working/retired & 39 & 45 & 38 \\
\hline \multicolumn{4}{|l|}{ English main spoken language at home } \\
\hline Yes & 92 & 94 & 78 \\
\hline No & 8 & 6 & 22 \\
\hline \multicolumn{4}{|l|}{ SSB every day causes health problems in adults } \\
\hline Not likely & 20 & 22 & \\
\hline Somewhat/very likely & 80 & 78 & \\
\hline
\end{tabular}

SSB every day causes health problems in children

\begin{tabular}{|c|c|c|c|}
\hline Not likely & 10 & 11 & \\
\hline Somewhat/very likely & 90 & 89 & \\
\hline \multicolumn{4}{|c|}{ Sugary drink consumption per week } \\
\hline $1-6$ times & 34 & 30 & \\
\hline $7+$ times & 14 & 13 & \\
\hline$\leq 25$ & 46 & 43 & 37 \\
\hline$>25$ & 50 & 53 & 63 \\
\hline Don't know & 4 & 4 & \\
\hline
\end{tabular}

Note: Comparisons of sex, age, education, employment status and language spoken at home were made with data sourced from the ABS. ${ }^{51}$ Where possible data were compared with adults aged 18+ years (age), in some cases, comparisons were made with adults aged 20+ years (gender, education and employment status) or all adults 15+ years (disadvantage and language spoken at home). Sugary drink consumption comparison was based on data from the 2011-2012 Australian Health Survey ${ }^{9}$ for adults aged 19+ years and pertained to consumption on the day prior to the interview, whereas in the current study, usual consumption was assessed. BMI comparison was based on data from the National Health Survey 2014-2015 for adults aged $18+$ years. $^{52}$

SSB, sugar-sweetened beverage. 
Table 3 Support for possible policy interventions in Australia (2017 survey, $n=3430$ )

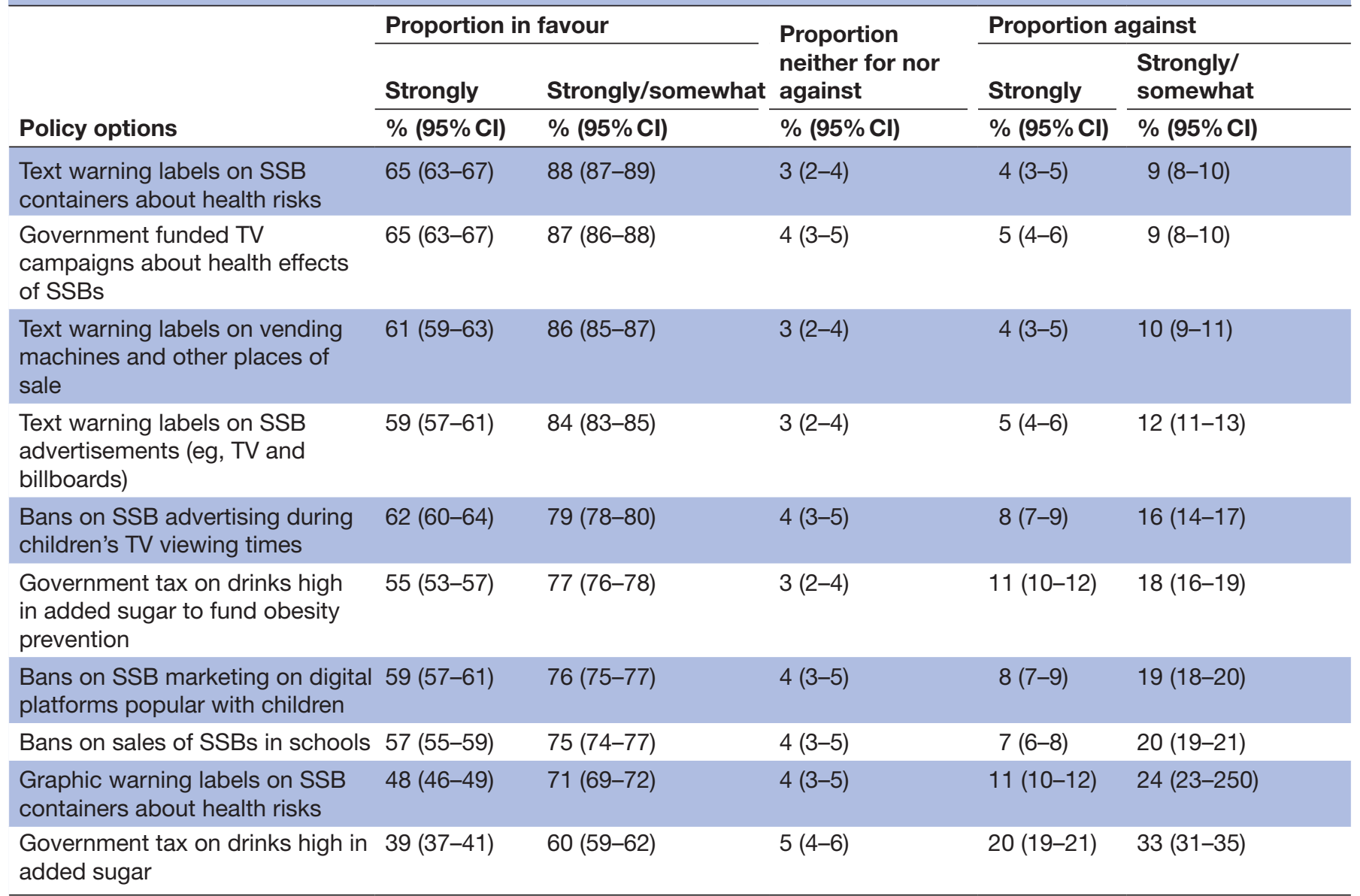

Note: Percentages do not add up to $100 \%$ as less than $2 \%$ reported 'don't know' or 'refused' for each response. 'Strongly/somewhat' reflects the cumulative proportion of those reporting they were either strongly or somewhat in favour or strongly or somewhat against.

SSB, sugar-sweetened beverage.

for initiatives aimed specifically at children (ie, bans on: SSB advertising at children viewing times, SSB marketing on digital platforms popular with children and the sale of all sugary drinks at schools). Older participants had a significantly lower likelihood than younger participants of favouring a government tax on drinks high in added sugar to fund obesity prevention, but a significantly greater likelihood of favouring the initiatives aimed specifically at children. Participants with higher levels of education were more likely to support all policy initiatives in table 5 .

\section{Knowledge and risk factor predictors of support for SSB policy} options

Participants with higher knowledge were frequently more likely to support policy initiatives. Significant associations were present between being cognisant of health risks of consuming SSBs in adults and level of support for 5 out of the 10 policy initiatives. Significant associations were present between being cognisant of health risks of consuming SSBs in children for 7 out of 10 initiatives.

Higher SSB consumption (7+ drinks per week) was significantly associated with decreased likelihood of support for all but one policy initiative. There were few associations with BMI, although those in the overweight or obese range were significantly less likely to report being in favour of government-funded TV campaigns about health effects of SSBs.

\section{DISCUSSION}

The study results show high community support for a range of SSB-specific policy initiatives, suggesting strong community appetite for government action around SSB consumption, with indications that this support is growing over time. Very high support was expressed for interventions warning consumers about the potential health effects of SSB consumption, with the highest support for text warning labels on sugary drink containers $(88 \%)$ and government-funded campaigns warning of health effects (87\%), closely followed by warnings on vending machines and other places of sale $(86 \%)$ and on advertisements $(84 \%)$. Consumers have the right to be informed about both the contents of the food and beverages they consume and the established health risks associated with frequent 


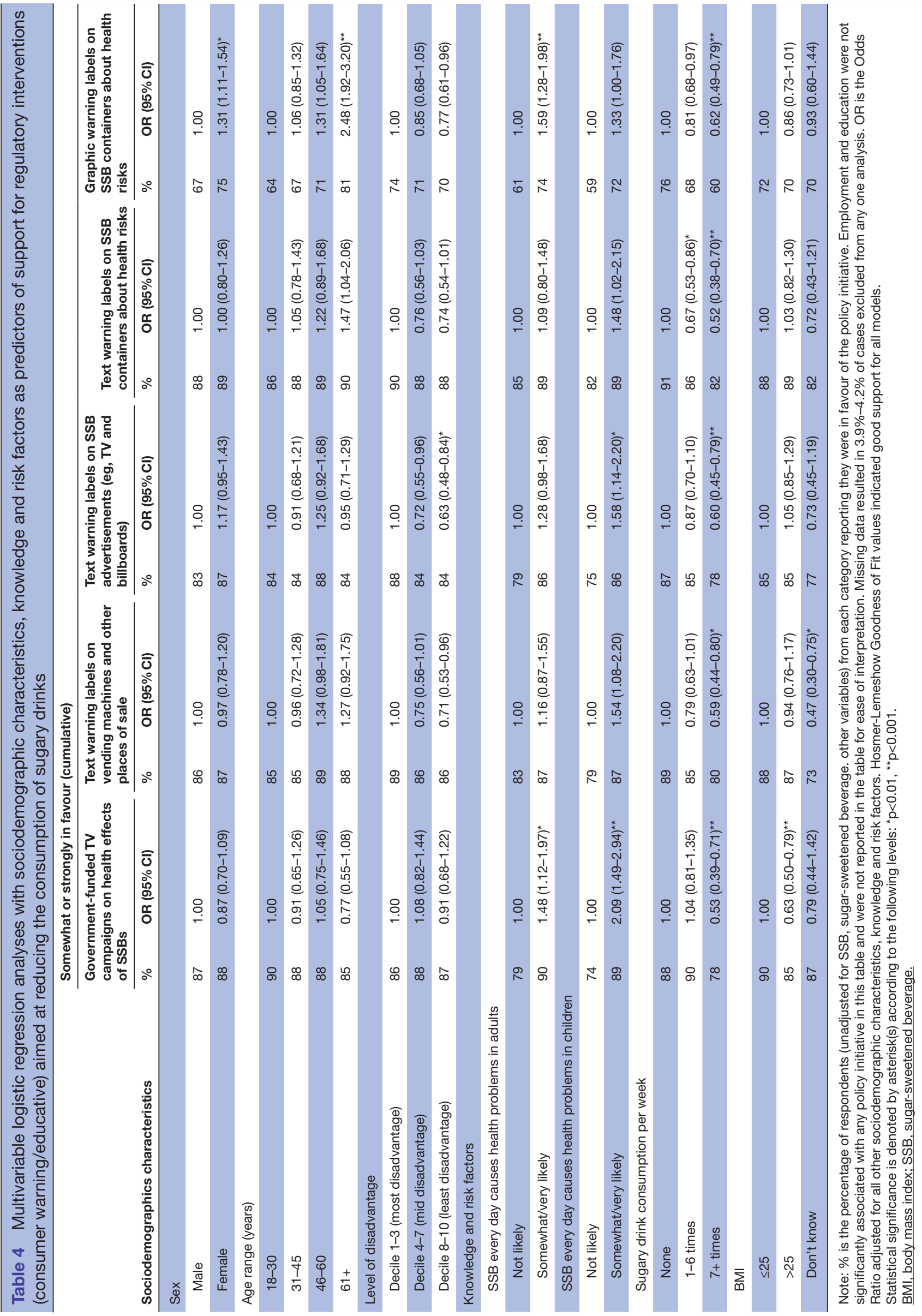

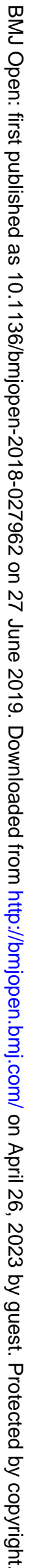




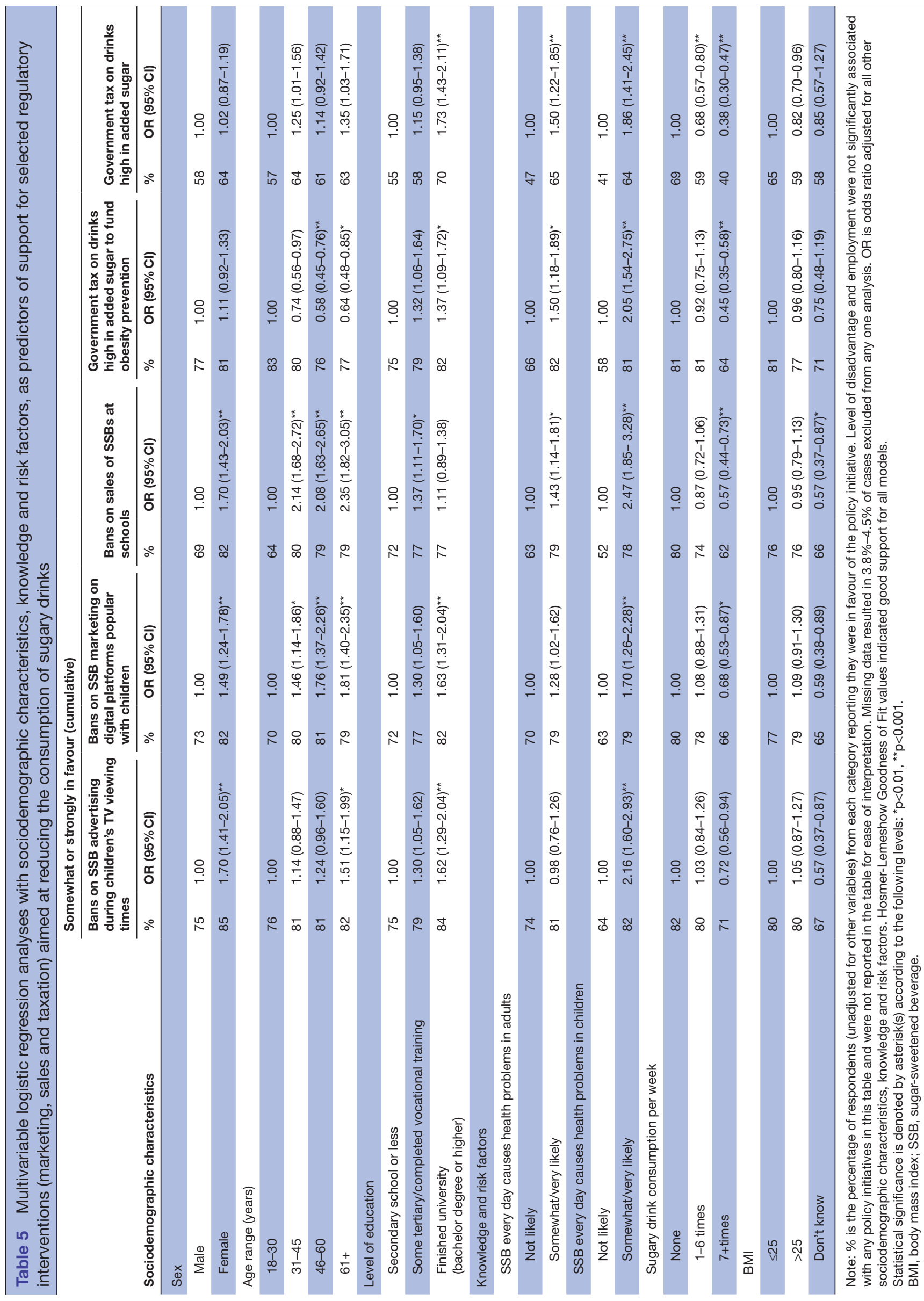

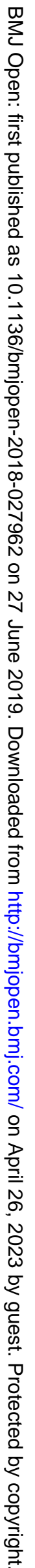


consumption. Governments have an important role in ensuring consumers have ready access to this information. Previous research shows information deficits exist regarding the sugar content of and health risks associated with SSBs. ${ }^{53}$ There is a clear need for, and public receptiveness to, government interventions warning of the health effects of frequent SSB consumption. Televised campaigns and text warning labels are prime opportunities given the very high levels of public support for these initiatives.

While front-of-pack label systems based on nutrient profiles are widespread on food and beverages, very few jurisdictions have implemented any form of warning label system. An exception is Chile, which has 'high in sugar' black stop-sign style warning labels that apply to foods and beverages that are high in sugar, with equivalent warnings for sodium, saturated fat and energy. ${ }^{67}$ Other South American countries, Israel and Canada have all foreshadowed their interest in similar warning label schemes. The city of San Francisco passed legislation for health effect warning labels on SSB advertisements, but it was blocked by sustained litigation from industry. ${ }^{68}$ Despite low realworld implementation, experimental studies continue to demonstrate the likely impact of SSB warning labels on knowledge and consumption. ${ }^{44} 4648-5069$ Of note, recent experimental research in Australia has found that graphic warning labels on food products tip consumers towards making healthier food choices ${ }^{69}$ and reduce automatic appetitive neural responses towards food cues. ${ }^{70}$

There was relatively high Australian population-level support for graphic health warnings on SSBs $(71 \%$ in 2017), compared with US-based experimental samples $(51 \%-63 \%)$. On-product health warnings are familiar to Australian consumers. Text warning labels have been in place on tobacco products for several decades. Australia was one of the first nations to introduce graphic health warnings on cigarette packets in 2006, with over 100 jurisdictions having advanced to graphic warnings internationally. ${ }^{71-74}$ Familiarity and awareness of impact may underpin Australians' level of support for graphic health warnings on SSBs. It also appears there may be increasing receptiveness among Australians to this form of government intervention.

Mass media campaigns rarely focus on the harmful health effects of unhealthy food or beverages and more frequently have taken a soft (eg, 'nudge') approach and/or promote fruit or vegetable consumption or physical benefits of healthier lifestyles. However, recent Australian state-based campaigns warning about specific serious health harms linked to SSBs have demonstrated effectiveness in changing beliefs, attitudes, behavioural intentions and behaviour. ${ }^{58} 7576$ These campaigns are reminiscent of the high-quality government-funded campaigns warning of the serious harms of tobacco that are long standing in Australia and, internationally, and have helped drive enormous shifts in behaviour (tobacco consumption) and social norms about smoking. ${ }^{77}$ A national campaign focused on increasing awareness of and concern about the serious health risks of frequent SSB consumption is now warranted.

In the present study, Australians expressed majority support for regulatory initiatives that would curb children's exposure to SSBs and their promotion via television advertising $(79 \%)$, marketing on digital platforms $(76 \%)$ and sales in schools $(75 \%)$. Our findings are consistent with support observed previously for the regulation of television and online marketing of unhealthy food and beverages targeting children. ${ }^{37}$ Support for restrictions on industry's ability to market to children likely reflects a recognition that children are more vulnerable as consumers and warrant greater protection. Given that Australian children are high consumers of SSBs $(47 \%)^{8}$ and levels of childhood overweight and obesity are unacceptably high $(26 \%),{ }^{78}$ government interventions to protect children from the heavy promotion of SSBs are overdue. Contextualising initiatives as protective of children's health would likely enhance community receptiveness.

While support in the present study for the taxation of drinks that are high in sugar was lowest among all the policies presented to participants, there was still majority support (60\% in 2017). Comparison with the 2014 survey data indicated an absolute increase in support in the order of $10 \%-15 \%$ over 3 years in one state, suggestive of growing public concern and receptiveness to this form of intervention. When taxation was linked to the provision of obesity prevention, public support was substantially higher $(77 \%)$, consistent with other studies, ${ }^{35} 37$ offering some insight into the relative increase in support that may occur with different policy framing. The approach of coupling taxation with other preventive interventions has demonstrated success in tobacco. ${ }^{77}$ Australian advocates are calling for a 'health levy' on SSBs as part of a broader suite of interventions. ${ }^{790} \mathrm{SSB}$ or 'soda' taxes have already been implemented around the world, ${ }^{10}$ have demonstrated effectiveness ${ }^{81}$ and have prompted reformulation by industry. ${ }^{82}$ Taking a 'comprehensive approach' that includes multiple policy components has demonstrated effectiveness in tobacco control, is consistent with the evidence in obesity prevention and may also align well with community preferences.

Overall, people who understood that daily SSB consumption by adults and/or children is likely to lead to health harms were more likely to support all forms of policy action. Continuing to raise community awareness of the health effects of frequent SSB consumption, which is important in its own right, may also increase community support for policy intervention. This is consistent with results from tobacco control and alcohol research showing increased support for policies after exposure to campaigns explaining health risks. ${ }^{25} 6083$

The finding that high consumers of SSBs were somewhat less receptive to policies in this study was not surprising given that pricing policies would impact directly on them. It is notable that despite lower levels of support relative to non-users, the majority of SSB consumers supported all 
proposed initiatives except stand-alone taxation (40\%). Taxation coupled with prevention had majority support $(64 \%)$.

\section{Limitations}

Cross-sectional population surveys can only capture the public's responses at one point in time, and reasons for support or lack of support for policy initiatives were not identified. However, characteristics of supporters and non-supporters (including knowledge about SSBs) provide insight into the identified differences in support. While some measures (eg, knowledge of harms of SSB consumption) had not been extensively validated, they were based on existing measures. ${ }^{60}$ Furthermore, while self-reported height and weight provide only an estimate of BMI, this is a frequently used method to approximate BMI and quantifies body size appropriately in Australians. ${ }^{84}$ To mitigate the risk of any social desirability response bias, the surveys were anonymous or deidentified. Overall, the 2017 survey yielded high-quality, nationally representative data that provide reliable evidence of the public's response to SSB policy options. The statebased survey (2014) provided insight into the views of those who resided in one state of Australia and therefore cannot be considered nationally representative. While comparisons were made between the state-based data of both samples for comparably worded policy initiatives only, differences in methodology as detailed in the method section need to be taken into account. Notably, the two methodological approaches resulted in different response rates with a lower rate observed for the CATI survey (which employed random digit dialling) versus the household face-to-face survey. Despite these limitations, the state-based data provided a historical reference and a valuable indication of how opinions towards an important health topic have changed over the last 3 years.

\section{CONCLUSIONS}

There is immediate public readiness for government action to reduce SSB consumption. The findings indicate very strong public support for multiple regulatory and educational interventions. There are indications that support for some initiatives has increased markedly over a short time frame. Framing policies as protecting children will likely result in greater levels of support, as will increasing knowledge of the harms associated with SSB consumption. Presenting taxation of SSBs in conjunction with other prevention initiatives is fundamental to community support.

Australia has a strong track record of intervening to change consumption behaviour in tobacco control. This success was underpinned by a comprehensive approach combining educative approaches with a strong regulatory framework. Australia should continue this successful approach to address SSBs. Given the Australian public's receptiveness, Australia would be well placed to be the first country in the world to introduce a comprehensive suite of interventions to address SSBs, including health warning labels, marketing restrictions, taxation and accompanying public education mass media campaigns.

Author affiliations

${ }^{1}$ School of Public Health, The University of Adelaide, Adelaide, South Australia, Australia

${ }^{2}$ Health Policy Centre, South Australian Health and Medical Research Institute, Adelaide, South Australia, Australia

${ }^{3}$ School of Psychology, University of Adelaide, Adelaide, South Australia, Australia ${ }^{4}$ Centre for Behavioural Research in Cancer, Cancer Council Victoria, Melbourne, Victoria, Australia

${ }^{5}$ School of Psychological Sciences, The University of Melbourne, Melbourne, Victoria, Australia

${ }^{6}$ School of Psychology, Curtin University, Perth, Western Australia, Australia

${ }^{7}$ College of Nursing and Health Sciences, Flinders University, Adelaide, South Australia, Australia

${ }^{8}$ Cancer Epidemiology and Population Health, University of South Australia, Adelaide, South Australia, Australia

${ }^{9}$ Discipline of Medicine, The University of Adelaide, Adelaide, South Australia, Australia

${ }^{10}$ Centre for Nutrition and GI Diseases, South Australian Health and Medical Research Institute, Adelaide, South Australia, Australia

${ }^{11}$ Obesity Policy Coalition and Alcohol and Obesity Policy, Cancer Council Victoria, Melbourne, Victoria, Australia

Contributors CLM conceptualised and led the design of the study with substantial contributions from KE, JD, MAW, SP, SJD, JC, DR, GW and JM. JD and KE coordinated the questions and conducted the analyses. CLM, KE and JD drafted the manuscript, and all authors contributed to the interpretation of data and critically revised the publication for important intellectual content. All authors approved the final manuscript and agreed to be accountable for all aspects of the work.

Funding This research was supported by a National Health and Medical Research Centre (NHMRC) Project Grant GNT 1120618 and Cancer Council's Beat Cancer Project on behalf of its donors and the State Government through the Department of Health. CM is supported by an NHMRC Career Development Fellowship and a Heart Foundation future leader fellowship, and MW is supported by a NHMRC Principal Research Fellowship.

Competing interests CLM, KE, JD, MAW, JC, DR, SJD and GW declared no competing interests. SP declares expert membership of Australian Government Health Star Ratings Committees, and JC declares membership of the Social Sciences and Economy Advisory Group of Food Standards Australia New Zealand.

Patient consent for publication Not required.

Ethics approval The study was approved by the University of Adelaide's Human Research Ethics Committee.

Provenance and peer review Not commissioned; externally peer reviewed.

Data sharing statement No additional data are available.

Open access This is an open access article distributed in accordance with the Creative Commons Attribution Non Commercial (CC BY-NC 4.0) license, which permits others to distribute, remix, adapt, build upon this work non-commercially, and license their derivative works on different terms, provided the original work is properly cited, appropriate credit is given, any changes made indicated, and the use is non-commercial. See: http://creativecommons.org/licenses/by-nc/4.0/.

\section{REFERENCES}

1. Sohn W, Burt BA, Sowers MR. Carbonated soft drinks and dental caries in the primary dentition. J Dent Res 2006;85:262-6.

2. Malik VS, Pan A, Willett WC, et al. Sugar-sweetened beverages and weight gain in children and adults: a systematic review and metaanalysis. Am J Clin Nutr 2013;98:1084-102.

3. Te Morenga L, Mallard S, Mann J. Dietary sugars and body weight: systematic review and meta-analyses of randomised controlled trials and cohort studies. BMJ 2012;346:e7492.

4. Te Morenga LA, Howatson AJ, Jones RM, et al. Dietary sugars and cardiometabolic risk: systematic review and meta-analyses of 
randomized controlled trials of the effects on blood pressure and lipids. Am J Clin Nutr 2014;100:65-79.

5. Van Rompay MI, McKeown NM, Goodman E, et al. Sugar-sweetened beverage intake is positively associated with baseline triglyceride concentrations, and changes in intake are inversely associated with changes in hdl cholesterol over 12 months in a multi-ethnic sample of children. J Nutr 2015;145:2389-95.

6. Vartanian LR, Schwartz MB, Brownell KD. Effects of soft drink consumption on nutrition and health: a systematic review and metaanalysis. Am J Public Health 2007;97:667-75.

7. Popkin BM, Hawkes C. Sweetening of the global diet, particularly beverages: patterns, trends, and policy responses. Lancet Diabetes Endocrinol 2016;4:174-86.

8. Australian Bureau of Statistics. Australian health survey: Nutrition first results - foods and nutrients, 2011-12. 2015. Consumption of sweetened beverages. Canberra. Report No: 4364.0.55.007: ABS.

9. World Health Organization. Guideline: Sugars intake for adult and children. Geneva: WHO, 2015.

10. Backholer K, Blake M, Vandevijvere S. Sugar-sweetened beverage taxation: an update on the year that was 2017. Public Health Nutr 2017;20:3219-24.

11. Colchero MA, Popkin BM, Rivera JA, et al. Beverage purchases from stores in Mexico under the excise tax on sugar sweetened beverages: observational study. BMJ 2016;352:h6704.

12. Silver LD, Ng SW, Ryan-lbarra $\mathrm{S}$, et al. Changes in prices, sales, consumer spending, and beverage consumption one year after a tax on sugar-sweetened beverages in Berkeley, California, US: A beforeand-after study. PLoS Med 2017;14:e1002283.

13. World Cancer Research Fund. Nourishing framework $2017 \mathrm{https}: / /$ www.wcrf.org/int/policy/nourishing-database (cited 6 Nov 2018).

14. Brownell KD, Warner KE. The perils of ignoring history: Big tobacco played dirty and millions died. How similar is big food? Milbank $Q$ 2009;87:259-94.

15. Brownell KD, Farley T, Willett WC, et al. The public health and economic benefits of taxing sugar-sweetened beverages. $N$ Engl $J$ Med 2009;361:1599-605.

16. Nixon L, Mejia P, Cheyne A, et al. "We're part of the solution": Evolution of the food and beverage industry's framing of obesity concerns between 2000 and 2012. Am J Public Health 2015;105:2228-36.

17. Mejia P, Nixon L, Womack R, et al. News coverage of ballot measures in Richmond and El Monte, California. 2012 Berkeley, CA: Berkley Media Studies Group, 2013. http://www.bmsg.org/sites/default/files/ bmsg_soda_tax_richmond_el_monte_prelim_report.pdf. (cited 10 Dec 2017).

18. Jou J, Niederdeppe J, Barry CL, et al. Strategic messaging to promote taxation of sugar-sweetened beverages: lessons from recent political campaigns. Am J Public Health 2014;104:847-53.

19. Diepeveen S, Ling T, Suhrcke M, et al. Public acceptability of government intervention to change health-related behaviours: a systematic review and narrative synthesis. BMC Public Health 2013;13:756.

20. Cullerton K, Donnet T, Lee A, et al. Effective advocacy strategies for influencing government nutrition policy: a conceptual model. Int $J$ Behav Nutr Phys Act 2018;15:83.

21. Cairney P. The role of ideas in policy transfer: the case of UK smoking bans since devolution. J Eur Public Policy 2009;16:471-88.

22. Dobrow MJ, Goel V, Lemieux-Charles L, et al. The impact of context on evidence utilization: a framework for expert groups developing health policy recommendations. Soc Sci Med 2006;63:1811-24.

23. Morrato EH, Elias M, Gericke CA. Using population-based routine data for evidence-based health policy decisions: lessons from three examples of setting and evaluating national health policy in Australia, the UK and the USA. J Public Health 2007;29:463-71.

24. Oliver K, Innvar S, Lorenc T, et al. A systematic review of barriers to and facilitators of the use of evidence by policymakers. BMC Health Serv Res 2014;14:2.

25. Martin N, Buykx P, Shevills C, et al. Population level effects of a mass media alcohol and breast cancer campaign: A cross-sectional pre-intervention and post-intervention evaluation. Alcohol Alcohol 2018:53:31-8.

26. Reynolds JP, Pilling M, Marteau TM. Communicating quantitative evidence of policy effectiveness and support for the policy: Three experimental studies. Soc Sci Med 2018;218:1-12.

27. Niederdeppe J, Heley K, Barry CL. Inoculation and narrative strategies in competitive framing of three health policy issues. $J$ Commun 2015;65:838-62.

28. Niederdeppe J, Shapiro MA, Kim HK, et al. Narrative persuasion, causality, complex integration, and support for obesity policy. Health Commun 2014;29:431-44.
29. Donaldson EA, Cohen JE, Rutkow L, et al. Public support for a sugar-sweetened beverage tax and pro-tax messages in a MidAtlantic US state. Public Health Nutr 2015;18:2263-73.

30. Gollust SE, Barry CL, Niederdeppe J. Americans' opinions about policies to reduce consumption of sugar-sweetened beverages. Prev Med 2014;63:52-7.

31. Rivard C, Smith D, McCann SE, et al. Taxing sugar-sweetened beverages: a survey of knowledge, attitudes and behaviours. Public Health Nutr 2012;15:1355-61.

32. Robles B, Kuo T. Predictors of public support for nutrition-focused policy, systems and environmental change strategies in Los Angeles County, 2013. BMJ Open 2017;7:e012654.

33. Curry LE, Rogers T, Williams P, et al. Public attitudes and support for a sugar-sweetened beverage tax in america's heartland. Health Promot Pract 2018:19.

34. Julia C, Méjean C, Vicari F, et al. Public perception and characteristics related to acceptance of the sugar-sweetened beverage taxation launched in France in 2012. Public Health Nutr 2015;18:2679-88.

35. Sundborn G, Thornley S, Lang B, et al. New Zealand's growing thirst for a sugar-sweetened beverage tax. N Z Med J 2015;128:80-2.

36. Morley B, Martin J, Niven P, et al. Public opinion on food-related obesity prevention policy initiatives. Health Promot J Austr 2012;23:86-91.

37. Sainsbury E, Hendy C, Magnusson R, et al. Public support for government regulatory interventions for overweight and obesity in Australia. BMC Public Health 2018;18:513.

38. Petrescu DC, Hollands GJ, Couturier DL, et al. Public acceptability in the uk and usa of nudging to reduce obesity: The example of reducing sugar-sweetened beverages consumption. PLoS One 2016;11:e0155995

39. Howse E, Freeman B, Wu JHY, Jhy W, et al. 'The university should promote health, but not enforce it': opinions and attitudes about the regulation of sugar-sweetened beverages in a university setting. BMC Public Health 2017;18:76.

40. Reisch LA, Sunstein CR, Gwozdz W. Viewpoint: Beyond carrots and sticks: Europeans support health nudges. Food Policy 2017;69:1-10.

41. Research Australia. Australia speaks! Research Australia opinion polling 2016. $2016 \mathrm{https}$ ://researchaustralia.org/wp-content/uploads/ 2016/01/Research-Australia_Polling-Report-2016.pdf (cited 21 Sep 2018).

42. Essential Media Communications. Sugar tax. 2018 http://www. essentialvision.com.au/sugar-tax. (cited 26 Apr 2018).

43. Mantzari E, Vasiljevic M, Turney I, et al. Impact of warning labels on sugar-sweetened beverages on parental selection: An online experimental study. Prev Med Rep 2018;12:259-67.

44. Acton RB, Hammond D. The impact of price and nutrition labelling on sugary drink purchases: Results from an experimental marketplace study. Appetite 2018;121:129-37.

45. Billich N, Blake MR, Backholer K, et al. The effect of sugarsweetened beverage front-of-pack labels on drink selection, health knowledge and awareness: An online randomised controlled trial. Appetite 2018;128:233-41.

46. Donnelly GE, Zatz LY, Svirsky D, et al. The effect of graphic warnings on sugary-drink purchasing. Psychol Sci 2018;29:1321-33.

47. Hammond D. Health warning messages on tobacco products: a review. Tob Control 2011;20:327-37.

48. Roberto CA, Wong D, Musicus A, et al. The influence of sugarsweetened beverage health warning labels on parents' choices. Pediatrics 2016:137:131.

49. VanEpps EM, Roberto CA. The influence of sugar-sweetened beverage warnings: a randomized trial of adolescents' choices and beliefs. Am J Prev Med 2016;51:664-72.

50. Bollard T, Maubach N, Walker N, et al. Effects of plain packaging, warning labels, and taxes on young people's predicted sugarsweetened beverage preferences: an experimental study. Int J Behav Nutr Phys Act 2016;13:1-7.

51. Bleich SN, Barry CL, Gary-Webb TL, et al. Reducing sugarsweetened beverage consumption by providing caloric information: how Black adolescents alter their purchases and whether the effects persist. Am J Public Health 2014; 104:2417-24.

52. Bleich SN, Herring BJ, Flagg DD, et al. Reduction in purchases of sugar-sweetened beverages among low-income Black adolescents after exposure to caloric information. Am J Public Health 2012;102:329-35.

53. Miller C, Wakefield M, Braunack-Mayer A, et al. Who drinks sugar sweetened beverages and juice? An Australian population study of behaviour, awareness and attitudes. BMC Obes 2019;6.

54. Dono J, Bowden J, Ettridge K, et al. Monitoring approval of new legislation banning smoking in children's playgrounds and public transport stops in South Australia. Tob Control 2015;24:519-20. 
55. Lal A, Mantilla-Herrera AM, Veerman L, et al. Modelled health benefits of a sugar-sweetened beverage tax across different socioeconomic groups in Australia: A cost-effectiveness and equity analysis. PLoS Med 2017;14:e1002326.

56. Australian Communications and Media Authority. Communications report 2015-16: Australian Government, 2017.

57. Glass DC, Kelsall HL, Slegers $C$, et al. A telephone survey of factors affecting willingness to participate in health research surveys. BMC Public Health 2015;15:1017.

58. Morley BC, Niven PH, Dixon HG, et al. Controlled cohort evaluation of the LiveLighter mass media campaign's impact on adults' reported consumption of sugar-sweetened beverages. BMJ Open 2018;8:e019574.

59. Morley BC, Scully ML, Niven PH, et al. What factors are associated with excess body weight in Australian secondary school students? Med J Aust 2012;196:189-92.

60. Boles M, Adams A, Gredler A, et al. Ability of a mass media campaign to influence knowledge, attitudes, and behaviors about sugary drinks and obesity. Prev Med 2014;67 Suppl 1(Suppl 1):S40-S45.

61. Australian Bureau of Statistics. Census of Population and Housing: Socio-economic Indexes for Areas (SEIFA), Australia. Cat. no. 2033.0.55.001. Canberra 2011.

62. Australian Bureau of Statistics. 2017 [cited 13 Nov 2018]. Available from:http://www.abs.gov.au/

63. Australian Communications and Media Authority. 2017 [cited 6 Nov 2018]. Available from:https://www.acma.gov.au/

64. The American Association for Public Opinion Research. Standard definitions: Final dispositions of case codes and outcome rates for surveys. 9th edn: AAPOR, 2016.

65. Australian Bureau of Statistics. Census of population and housing: Reflecting Australia - stories from the census, 2016. 2017.0. Australia: ABS, 2018.

66. Australian Bureau of Statistics. National health survey: First results. Report no. 4364.0.55.001. Canberra, Australia: ABS, 2015.

67. Kanter R, Vanderlee L, Vandevijvere S. Front-of-package nutrition labelling policy: global progress and future directions. Public Health Nutr 2018;21:1399-408.

68. Falbe J, Madsen K. Growing momentum for sugar-sweetened beverage campaigns and policies: Costs and considerations. Am J Public Health 2017;107:835-8.

69. Rosenblatt $\mathrm{DH}$, Bode $\mathrm{S}$, Dixon $\mathrm{H}$, et al. Health warnings promote healthier dietary decision making: Effects of positive versus negative message framing and graphic versus text-based warnings. Appetite 2018:127:280-8.

70. Rosenblatt DH, Summerell P, Ng A, et al. Food product health warnings promote dietary self-control through reductions in neural signals indexing food cue reactivity. Neuroimage Clin 2018:18:702-12.

71. Society CC. Cigarette package health warnings: International Status Report. 5th Edn: Canadian Cancer Society, 2016.

72. Miller CL, Hill DJ, Quester PG, et al. Response of mass media, tobacco industry and smokers to the introduction of graphic cigarette pack warnings in Australia. Eur J Public Health 2009;19:644-9.

73. Miller CL, Hill DJ, Quester PG, et al. The impact of Australia's new graphic cigarette packet warnings on smokers' beliefs and attitudes. Australasian Marketing Journal 2011;19:181-8.

74. Miller CL, Quester PG, Hill DJ, et al. Smokers' recall of Australian graphic cigarette packet warnings \& awareness of associated health effects, 2005-2008. BMC Public Health 2011;11:238.

75. Barragan NC, Noller AJ, Robles B, et al. The "sugar pack" health marketing campaign in Los Angeles County, 2011-2012. Health Promot Pract 2014;15:208-16.

76. Farley TA, Halper HS, Carlin AM, et al. Mass media campaign to reduce consumption of sugar-sweetened beverages in a rural area of the united states. Am J Public Health 2017;107:989-95.

77. Wakefield MA, Coomber K, Durkin SJ, et al. Time series analysis of the impact of tobacco control policies on smoking prevalence among Australian adults, 2001-2011. Bull World Health Organ 2014:92:413-22.

78. Australian Bureau of Statistics. Australian Health Survey: Updated Results, 2011-2012, 2013. Cat. no. 4364.0.55.003. Canberra.

79. Rethink sugary drink. Health levy on sugar-sweetened beverages. Rething sugary drink position statement, 2017.

80. Sacks $\mathrm{G}$ for the Food-Epi Australia project team. Policies for tackling obesity and creating healthier food environments: Scorecard and priority recommendations for australian governments. Melbourne: Deakin University, 2017.

81. Colchero MA, Rivera JA, Popkin BM, et al. Sustained consumer response: Evidence from two-years after implementing the sugar sweetened beverage tax in mexico. Health Aff 2017;36:564-71.

82. The Lancet Diabetes Endocrinology. Sweet success: will sugar taxes improve health? Lancet Diabetes Endocrinol. 2017;5:235.

83. Niederdeppe J, Kellogg M, Skurka C, et al. Market-level exposure to state antismoking media campaigns and public support for tobacco control policy in the United States, 2001-2002. Tob Control 2017:tobaccocontrol-2016-053506.

84. Ng SP, Korda R, Clements M, et al. Validity of self-reported height and weight and derived body mass index in middle-aged and elderly individuals in Australia. Aust N Z J Public Health 2011;35:557-63.

85. Bowring AL, Peeters A, Freak-Poli R, et al. Measuring the accuracy of self-reported height and weight in a community-based sample of young people. BMC Med Res Methodol 2012;12:175. 